\title{
IMPERIALISMO VERDE: NOVAS DOMINAÇÕES EM NOVOS TEMPOS
}

\author{
IMPERIALISMO VERDE: NUEVOS DOMINIOS EN NUEVOS TIEMPOS
}

\section{GREEN IMPERIALISM: NEW DOMINATIONS IN NEW TIMES}

DOI: http://10.9771/gmed.v13i2.45068

\author{
Amanda Monteiro Stelitano Medeiros ${ }^{1}$ \\ Gabriel Gonçalves Ribeiro²
}

\begin{abstract}
Resumo: As transformações dos diferentes ciclos de capital e poder levaram à organização hierárquica, expansionista e competitiva entre os Estados inseridos na dinâmica capitalista liberal. A imposição da supremacia e a reafirmação de poder dos impérios capitalistas se expande para além das transações financeiras e comerciais; englobando as estruturas políticas e militares, ideológicas, sociais e ecológicas como meios de manutenção dos grandes impérios. O objetivo deste trabalho se dá ao estabelecer a relação entre a dominação internacional e teorias do imperialismo na área ambiental através dos conceitos essenciais apresentados.
\end{abstract}

Palavras-chave: Imperialismo Verde. Financeirização. Dependência.

Resumen: Las transformaciones de los diferentes ciclos de capital y poder llevaron a una organización jerárquica, expansionista y competitiva entre Estados insertos en la dinámica capitalista liberal. La imposición de la supremacía y la reafirmación del poder por parte de los imperios capitalistas se extiende más allá de las transacciones financieras y comerciales; abarcando estructuras políticas y militares, ideológicas, sociales y ecológicas como medio para mantener grandes imperios. El objetivo de este trabajo es establecer la relación entre la dominación internacional y las teorías del imperialismo en el área ambiental a través de los conceptos esenciales presentados.

Palabras clave: ImperialismoVerde. Financiarización. Dependencia.

Abstract: The transformations of the different cycles of capital and power led to a hierarchical, expansionist and competitive organization among the states inserted in the liberal capitalist dynamics. The imposition of supremacy and the reaffirmation of power by capitalist empires expands beyond financial and commercial transactions; encompassing political and military, ideological, social and ecological structures as means of maintaining the great empires. The aim of this work is to establish the relationship between international domination and theories of imperialism in the environmental area through the essential concepts presented.

Keywords: Green Imperialism. Financialization. Dependency.

\section{Introdução}

A teoria de Marx, ao tentar explicar a construção das relações entre os Estados-nações e suas posições dentro do jogo de poderes, é clara ao apontar que o sistema liberal econômico se sustenta e se fortalece através das relações desiguais de expansão da exploração de Estados detentores de mais poder e com maior acúmulo de capital sobre Estados mais fracos e vulneráveis reféns da estrutura monetária e financeira imposta. Giovanni Arrighi (2013, p. 28-74), ao aprofundar seus estudos na origem dos ciclos

Germinal: marxismo e educação em debate, Salvador, v.13, n.2, p. 134-150, ago. 2021. ISSN: 2175-5604 
hegemônicos na História, reconhece que a hegemonia se dá pela imposição da supremacia de um ator e/ou um grupo sob os mais fracos de poder. Entretanto, essa dominação pode se manifestar de formas distintas; de forma coercitiva de força, com ameaças de guerra e a consequente instabilidade da estrutura como um todo; ou também, a manifestação da dominação através de elementos ideológicos, morais e intelectuais.

O conceito de 'hegemonia mundial' aqui adotado, no entanto, refere-se especificamente à capacidade de um Estado exercer funções de liderança e governo sobre um sistema de nações soberanas. (...) Esse poder é algo maior e diferente da “dominação" pura e simples. É o poder associado à dominação, ampliada pelo exercício da "liderança intelectual e moral. (ARRIGHI, 2013, p.27)

David Harvey (2006, p. 107-120) compreende a ação imperialista no excesso de domínio das esferas estruturais concentradas nas mãos de um só ator, logo, os EUA não se mostravam apenas como o hegemon em questão, mas sim como uma superpotência imperial que, somada com a característica territorialista e expansionista, forçava uma necessidade de exportar a exploração do trabalho e da matéria além das fronteiras para ampliar seus lucros e explorar a mão-de-obra mais barata.

O ponto central do imperialismo é a monopolização do capital. O capital é uma forma de poder e, como citado anteriormente, não existe uma forma de poder homogênea e estática; aquele que se estrutura financeiramente e firma sua posição de autoridade necessita do excedente para acumulação ampliada e, com isso, a reprodução dos padrões de produção da máquina de mercado sobre aqueles que não estão inseridos nos grupos aliados e dominantes da estrutura financeira capitalista. Logo, assim como a estrutura interestatal é vista como instável e suscetível a ciclos de crise pela essência conflitiva e competitiva, a teoria imperialista, pela ótica de Harvey, afirma que a instabilidade no estado de harmonia e cooperação internacional é tão natural quanto os ciclos de concentração financeira do capital. A ordem liberal e a estrutura capitalistas são, por essência, fomentadas e sustentadas pelas políticas opressoras e dominadoras (HARVEY, 2005, p. 97).

Essas estruturas de dominação internacional desenvolvem-se em diversas áreas, utilizando tanto coerção quanto o capital como mecanismos de controle. Uma dessas áreas é a ambiental, com relação à qual há diversas dinâmicas de retirada de recursos naturais. Essas dinâmicas, no entanto, não se restringem à ideia básica do imperialismo clássico que trata da relação entre colônias conquistadas, fontes de matérias-primas, e de metrópoles que utilizam-nas como mercados para manufaturados. Há dinâmicas de custos ambientais que são por vezes ignoradas ao se tratar das disparidades em relações entre países. Sendo assim, o objetivo deste artigo é promover um debate entre as teorias clássicas e modernas do imperialismo para com o conceito de imperialismo verde ou ecológico.

Antes de seguir para a discussão teórica, é prudente apresentar uma breve adição quanto à interdisciplinaridade presente neste artigo, o que será feito através da utilização de comentários de Wallerstein sobre o conceito de "interciência". A necessidade desta apresentação se justifica pela clara união utilizada aqui entre ciências humanas, particularmente a política e a econômica, e ciências da 
natureza. É útil ao desenvolvimento deste artigo citar os benefícios apresentados por autores como Wallerstein e Braudel quanto à interdisciplinaridade.

Primeiramente, apresentamos uma análise, feita por Wallerstein (2001, p. 3-12), da "interciência" defendida por Braudel, que nunca explicou diretamente o que o termo significa, mas expressou isso em discursos e artigos. A crítica de Braudel é desenvolvida sobre a falta de unidade nas ciências sociais, que têm uma diversidade competitiva entre os campos que mais parecem funcionar como "pátrias", com "linguagens" diferentes e que, ao mesmo tempo, são imperialistas umas sobre as outras (BRAUDEL, 1978, p. 79 e 80). Sobre quão "unitária” a interciência deveria ser e quais disciplinas deveria abarcar, a resposta parece ser "a totalidade do que tem sido exibido sob os rótulos das ciências sociais ou ciências humanas e muito além disso" (WALLERSTEIN, 2001, p. 5, tradução nossa). No mesmo artigo, Wallerstein cita um trecho no qual Braudel comenta que a simples união interdisciplinar entre dois campos, como história e geografia ou economia, seria insuficiente (ibidem, p. 6). Braudel (1978, p. 84) chega mesmo a dizer que "duas ciências próximas se repelem" e que tais uniões "exigem demasiado", estando a melhor resposta ou, como diz, a "sabedoria" na baixa simultânea dos "direitos de aduana" das diversas ciências, resultando numa circulação de ideias e técnicas favorecida e na formação de uma linguagem comum. Pode-se dizer que o objetivo de Braudel, ao defender a interciência a partir da década de 1960, era criar um “congresso ecumênico" que iria além desse racha epistemológico entre ciências naturais e sociais (WALLERSTEIN, 2001, p. 9 e 10). Wallerstein demonstra concordar e celebrar as intenções de Braudel. É importante lembrar do tratamento do ser humano como dependente da realidade física na qual é encontrado, mais especificamente sob a qualidade de "máquina vivente" apresentada por Braudel (1978, p. 144). Ao enxergar o indivíduo desta forma, vulnerável aos fatores ambientais, animados ou inanimados, "recolocado, enquanto tal, nas condições geográficas do vasto mundo", também é possível estabelecer uma relação sob a qual os Estados, as sociedades, os agrupamentos e representações de indivíduos, também são sensíveis ao ambiente. Esta sensibilidade é mais um elemento que diz respeito à sobrevivência e aos interesses do Estado e, por tanto, também deve ser considerada nas análises sistêmicas.

Considerando o contexto da pandemia de covid-19 que varre o mundo, é relevante trazer as possíveis conexões entre humanidade e ambiente da forma mais clara possível, visando otimizar os processos de geração de conhecimento para os interesses da sociedade e dos Estados-nação. Apesar do ponto central deste artigo ser dedicado a questões de desenvolvimento econômico, é válido lembrar que questões ambientais sempre trazem impactos biológicos e sanitários consideráveis e, várias vezes, pouco compreendidos. A pandemia de covid-19 é só um dos exemplos de possíveis eventos que podem ser desencadeados por desequilíbrios populacionais e ecológicos, causando contatos delicados entre agentes patológicos de outros seres vivos para com o humano, além de outros eventos como o aquecimento global, a desertificação, poluição exacerbada e deformação dos ciclos hídricos. 


\section{Teorias clássicas do imperialismo e da dependência}

Autores clássicos, ao tratar da questão do imperialismo entre fins do século XIX e início do XX, desenvolveram visões variadas que podem ser classificadas, segundo Marcos Del Roio (2007, p. 3337), entre "social-reformistas" e "revolucionárias". A diferença primária entre estas percepções era quanto à consideração sobre o que o imperialismo é para a ordem capitalista. Enquanto os reformistas tratavamno como uma aberração em relação aos métodos de expansão da hegemonia burguesa, os marxistas revolucionários enxergam no imperialismo um estágio natural da expansão da ordem capitalista.

A hegemonia burguesa é tacitamente aceita pela visão social-reformista, que considerava práticas imperialistas violentas como alternações contrárias à "missão civilizatória e democrática", objetivos pelo colonialismo. John Hobson, em livro de 1902, critica o imperialismo motivado pela necessidade de expansão de mercados e argumenta que uma das causas para este problema é o baixo poder de consumo do proletariado europeu, enquanto um dos resultados é a criação de uma classe que se beneficia da especulação financeira movida pelo imperialismo. Complementar à compreensão de Hobson, a contribuição de Rudolf Hilferding explica que a formação de oligopólios e monopólios a nível nacional projeta a competição por mercados para o plano internacional, para o qual são exportados capitais excedentes e buscados novos mercados, além de mão de obra e matérias-primas mais baratas. A visão do imperialismo bélico como uma deturpação passageira do capitalismo também foi compartilhada por Kautsky, argumentando que ela era motivada por "classes agrárias parasitárias e de setores da burguesia a elas vinculados", enquanto a maior parte da burguesia tinha interesse numa expansão pacífica dos mercados (DEL ROIO, 2007, p. 34). A visão reformista apresentava uma lógica através da qual o capitalismo se desenvolveria pacificamente para uma forma que, segundo Hilferding, seria organizada pelo capital financeiro e, segundo Kautsky, seria levado "por super monopólios a um mercado mundial unificado por um ultra-imperialismo também unificado", resultando na passagem para o socialismo.

Enquanto isso, os marxistas revolucionários, apesar de também haver divergências internas, observavam a guerra não como um distúrbio passageiro, mas como elemento intrínseco ao imperialismo capitalista, considerado uma fase avançada do capitalismo. Rosa Luxemburgo, em 1913, observa a competição pelas zonas coloniais pré-capitalistas, citando o exemplo da Rússia rural, e argumenta que a concorrência imperialista resultaria num estreitamento de laços entre Estado, capitalistas e guerra. Havia muito mais atenção à conquista militar na teoria de Luxemburgo, enquanto a exportação de capitais não recebeu tanta atenção. Esgotados os espaços que poderiam ser disputados belicamente, seguiriam a estagnação econômica e uma tentativa de contínua ampliação produtiva através da intensificação da exploração do operariado. Nestas condições, a revolução socialista ocorreria. Nikolai Bukharin, em 1915, apresenta sua crítica e não só adota a determinação do imperialismo como uma fase do capitalismo, caracterização pela existência de monopólios e de exportação de capitais, como discorda de Luxemburgo na questão do destino do capitalismo após a expansão total de um sistema global. Bukharin argumentava 
que o capitalismo poderia continuar a se desenvolver de forma organizada, diferentemente da estagnação percebida por Luxemburgo, mas também sem a perspectiva de organização capitalista homogênea apresentada pelos reformistas, particularmente por Hilferding, que esperavam um capitalismo organizado, racional e que levaria ao socialismo sem alterações de acordo com o contexto político ou econômico de cada país. Ao contrário, Bukharin ofereceu uma visão de heterogeneidade no mercado global, com uma divisão do trabalho entre países imperialistas e colonizados. O imperialismo, fase superior do capitalismo, redigido por Lênin e publicado entre 1916 e 1917, traz contribuições como a caracterização do imperialismo iniciado na década de 1880 como uma fase do capitalismo, possibilitada pela fusão do capital financeiro e industrial que, por sua vez, possibilita a existência de monopólios ou oligopólios e do capital rentista, que se reproduz sozinho. É considerado por Lenin um novo modo de imperialismo que, além de exacerbar as contradições econômicas entre império e colônia, também vincularia o capital financeiro ao setor bélico e ao Estado, gerando mais militarização e guerras para a manutenção dos interesses do setor financeiro. Por fim, também havia a percepção da formação de uma "aristocracia operária". Esse grupo do operariado defensor do social-reformismo seria formado, na visão de Lênin, pela expansão do capital e da especulação, que alçaria alguns grupos operários bem organizados a níveis de vida superiores, enquanto Luxemburgo observava esse grupo como formado pela fase pacífica de expansão capitalista e pela legalidade burguesa. Compartilhando da ideologia social-reformista, a aristocracia operária seria vinculada aos interesses imperialistas, motivada por uma aproximação do padrão de vida ao nível da pequena burguesia, e posicionaria-se contra a vertente marxista revolucionária (DEL ROIO, 2007, p. 35-39).

A pressão vertical e esmagadora provinda da hierarquia dos impérios para a subordinação e dependência das colônias é o ponto crucial para o desenvolvimento da Teoria da Dependência, esta que ilustra além das limitações econômicas para o crescimento da periferia colonial, mas também a imposição da desigualdade nas estruturas sociais como forma de manutenção da hierarquia e domínio do império.

Theotonio dos Santos, Vânia Bambirra, Ruy Mauro Marini e André Gunder Frank foram nomes essenciais para a elaboração de uma linha teórica, banhados pela visão marxista e sua corrente literária, que explicasse os fenômenos herdados pelo imperialismo de forma que os Estados mais poderosos no controle do sistema global sustentassem seu crescimento exponencial às custas dos Estados mais vulneráveis através da exploração e subordinação ideológica, política e comercial.

Dos Santos classifica o processo de dependência como:

Por dependência entende-se uma situação em que a economia de certos países é condicionada pelo desenvolvimento e expansão de outra economia à qual a primeira está sujeita. A relação de interdependência entre duas ou mais economias, e entre estas e o comércio mundial, assume a forma de dependência quando alguns países (os dominantes) podem se expandir e podem ser autossustentáveis, enquanto outros países (os dependentes) podem fazer isso apenas como um reflexo dessa expansão, que pode ter um efeito 
positivo ou negativo em seu desenvolvimento imediato. (DOS SANTOS, 1970a, p. 231)

Como pontos principais da pesquisa, a TMD especifica que a dependência econômica foi exposta nos países latino-americanos como forma de inserção na economia mundial pós guerra no sistema de monopólio capitalista e imperialismo e como oportunidade de estruturação socioeconômica. Esta linha compreende os diferentes processos de industrialização entre os países da América Latina, tendo: 1) aqueles que iniciaram sua industrialização no período pré-Guerra, com políticas desenvolvimentistas, substituição da indústria nacional para o capital estrangeiro e os processos de revolução entre as classes sociais internas, como o Brasil, por exemplo; 2) aqueles que só iniciaram o processo de industrialização e substituição das exportações no pós-Guerra, recebendo uma assistência financeira maior de capital estrangeiro para recuperar o "atraso" econômico na inserção do sistema capitalista mundial e, por consequência, seguindo de forma mais controlada as imposições estrangeiras; analisando como o status quo de economia dependente influenciou no processo de criação históricodesenvolvimentistas de tais Estados (DOS SANTOS, 2015, p. 11-13).

Torna-se claro o entendimento de que a necessidade para essa linha teórica alternativa surge em contrapartida ao domínio ideológico neoliberal e a visão utópica de um mundo globalizado e interdependente com uma universalidade e manutenção da paz orgânica. A obra de Vânia Bambirra (1972) debate sobre o efeito do desenvolvimento dependente no setor econômico, gerando nos países um processo de monopolização interna como espelho dos processos externos do arranjo das hegemonias internacionais, enquanto o centro amarrava o controle nos países periféricos através do capital estrangeiro e das imposições nos sistemas de produção básicos. Tais imposições afetaram também nas esferas políticas e sociais, uma vez que, assim como a apropriação por imposição do modelo econômico capitalista foi usada como instrumento de barganha entre o assistencialismo estrangeiro nos setores industriais, o período de desenvolvimento destes países foi marcado pela imposição histórica do alinhamento político para efeitos de "apoio" internacional, fomentando a polarização interna entre os grupos políticos e classes dominantes e dominados (BAMBIRRA, 2012, p. 215-217).

É de suma importância destacar que a Teoria Marxista da Dependência (TMD) tem um papel essencial para o entendimento da visão do mundo imperialista pela perspectiva das colônias e não dos colonizadores. Enquanto a literatura clássica marxista que abordava as relações de fluxos e evoluções das hegemonias para impérios e seus ciclos de poder seguia com uma visão oriunda de países centrais e industrializados, a TMD utiliza desta base literária e teórica para a adaptação de visão e construção da sua própria linha de pensamento pela ótica periférica.

O processo de introdução dos países industrializados e desenvolvidos ao sistema capitalista imperialista não pode ser descrito com as mesmas consequências que a entrada forçada e programada dos países em desenvolvimentos e fortemente dependentes dos investimentos do capital estrangeiro para sua industrialização. Enquanto acontecia essa importação dos capitais e esse indireto controle dos países 
desenvolvidos não só ao processo de desenvolvimento, mas também, ao processo de acumulação de capital da periferia, a importação de políticas de alinhamento ideológico e pressão da financeirização se estendia aos setores além do econômico.

Não cabe a este trabalho se aprofundar nos debates entre os teóricos marxistas sobre as limitações de ambas as linhas, contudo, visto os diversos argumentos apresentados sobre os instrumentos de dominação do imperialismo capitalista para a subordinação e dependência contínua das colônias e a manutenção do desenvolvimento condicionado e restrito em prol do crescimento de Estados centrais; torna-se necessário trazer à luz de questionamento se de fato a Teoria Marxista da Dependência aproxima-se melhor da realidade periférica e suas consequências perante a inserção ao sistema capitalista e o domínio imperialista daqueles Estados maiores que dominam suas relações através do investimento e acumulação primitiva e violenta de seus recursos e matérias-primas.

\section{O imperialismo verde e a periferização ambiental}

O imperialismo verde pode ser compreendido a partir de duas dinâmicas principais que serão discutidas nesta seção do artigo. Essas duas dinâmicas são relacionadas aos custos ambientais, sendo que a primeira trata da geração deles enquanto a segunda trata de como cada Estado pode lidar com os custos gerados. A partir de diferentes posições no sistema internacional e de diferentes configurações institucionais e legislativas internas, países têm seus próprios desenvolvimentos na relação entre Estado e meio ambiente. Assim, há situações nas quais o nível de desenvolvimento ou o tipo de regime de países está ligado a suas legislações ambientais. Exemplos citados por Sommer et al. (in: FREY et al, 2019, p. 167-171) demonstram situações nas quais países com governos autoritários ou periféricos utilizam a isenção ou a limitação de suas legislações ambientais para atrair investimentos ou tornar suas exportações mais atraentes. É comum que empresas extrativistas de países desenvolvidos se aproveitem desse cenário, reduzindo custos que, em contrapartida, deixam rastros ambientais em formas de desastres naturais, poluição e outros desequilíbrios, caracterizando uma troca ambiental desigual. A segunda dinâmica, tratando de como os Estados lidam com os custos, caracteriza-se por uma situação na qual países centrais, com legislações ambientais e tecnologias desenvolvidas a nível de atender às demandas das legislações, "exportam" suas exigências a países com capacidades tecnológicas e financeiras inferiores. O resultado costuma ser a necessidade das economias periféricas importarem técnicas e tecnologias dos desenvolvidos ou ter suas exportações prejudicadas.

Hestermeyer (2012, p. 49-52) critica, principalmente, o conceito universal e horizontal que o projeto de inserção da financeirização de recursos naturais e ecológicos nas relações econômicas e comerciais da agenda global remetem aos países em desenvolvimento. A crítica de Hestermeyer se constrói uma vez que a capacidade de desenvolvimento e produção, e consequentemente, de padrões de 
consumo e necessidade de exploração são bastante divergentes entre os países, principalmente em uma perspectiva dos Estados centrais para a periferia global. Segundo o autor:

(...) os países em desenvolvimento não possuem os recursos financeiros ou know-how técnico para realizar as mesmas obrigações que os países desenvolvidos. Insistir em tratamento formalmente igual impediria os países em desenvolvimento de participar dos regimes ambientais. (HESTERMEYER, 2012, p. 52)

Em um trecho de sua obra sobre a cooperação entre os Estados para a preservação ambiental, Hestermeyer destaca:

Obrigações diferenciadas não são apenas um imperativo de justiça global reminiscente do "poluidor-pagador", já que os países desenvolvidos têm desempenhado um grande papel em causar problemas ambientais globais. Significa também que os países em desenvolvimento não possuem os recursos financeiros ou know-how técnico para realizar as mesmas obrigações que os países desenvolvidos. Insistir em tratamento formalmente igual impediria os países em desenvolvimento de participar dos regimes ambientais. (HESTERMEYER, 2012, p. 52)

Cabe trazer para o debate o acompanhamento da apresentação do conceito de "inserção do capital na paisagem" trazido por Smith (1984, p. 97 apud MISOCZKY E BÖHM, 2012, p. 549) na clara necessidade do mercado liberal de utilizar os bens naturais e comuns como objetos mercantilizados e, consequentemente, acumulados para o crescimento do capital. Esse processo de inserção da preocupação ecológica e da necessidade de captação natural na pauta global encaminhou-se em paralelo com as exportações ideológicas das políticas neoliberais como potencializador das trocas desiguais voltadas ao desenvolvimento e industrialização. Misoczky e Böhm (2012, p. 546-568) apontam que, se em um ciclo histórico anterior, a participação da captação e acumulação dos bens naturais no crescimento econômico se caracterizava pelas práticas agrícolas e extrativistas, a nova visão mercantilista dos recursos ambientais funciona como valor de troca em uma troca desigual (MISOCZKY E BÖHM, 2012, p. 548).

À luz da interseção entre a financeirização ambiental e a abertura do mercado ecológico como forma de acumulação e expansão dos impérios de poder, a contribuição de David Harvey (2006, p. 107120) em seu ensaio sobre o novo imperialismo e suas formas de ampliação se caracteriza através do conceito de "acumulação por espoliação" e o capitalismo com característica predatória e ilimitada. Em um primeiro momento, Harvey (2006, p. 111-120) analisa as transformações dos novos ciclos do capitalismo moderno além do restrito ao âmbito econômico-monetário; seguindo a forma orgânica do capitalismo liberal em desdobramento ilimitado através da expansão e amplificação de territórios e setores, permeando entre as esferas político-sociais e, não distante, ambientais. A necessidade de reafirmação do poder ilimitado e da necessidade de variedade para a acumulação do capital em suas diversas formas caracterizou a nova face do capitalismo moderno (HARVEY, 1989 apud ALMEIDA FILHO E PAULANI, 2011, p. 250)

Para o geógrafo, a comodificação da força de trabalho e a supressão de formas alternativas de produção e consumo; processos coloniais, neocoloniais e imperiais de apropriação de ativos; e a financeirização são umas das principais ferramentas que caracterizam a acumulação moderna de capital de 
forma a superar as crises de instabilidade geradas pelo crescimento desordenado e inflação de recursos em reserva (HARVEY, 2006 apud MISOCZKY E BÖHM, 2012, p.554).

Uma das exemplificações mais claras é a base extrativista das economias latino-americanas e a necessidade de exploração dos recursos naturais cada vez em maior escala para suprir as necessidades do mercado global em commodities e matérias primárias. A obra de Atílio Borón engloba uma crítica ao processo de industrialização induzido na América Latina e como a industrialização progressista no continente tornou-se sinônimo de exportação e extração. Logo, uma cadeia de práticas prejudiciais ao meio ambiente foi consolidada como base da economia latino-americana: a ideologia do export led growth (crescimento conduzido pela exportação) seguida por uma rápida mercantilização dos bens naturais para suportar essa ideologia, gerando uma race to the bottom, no qual os países abrem mão das suas políticas ambientais e mecanismos de proteção para acompanhar as demandas do centro global; e, tudo adequado para uma atração do investimento estrangeiro direto (IDE) à qualquer custo. (BORÓN, 2012, p. 134).

Diante disto, Borón também introduz o conceito de ecossocialismo de Barry Commoner 3 (1971), o qual é explicitado às práticas do imperialismo verde supracitadas neste texto. Para o estadunidense, os países do Sul Global jamais alcançarão o nível de riqueza e estabilidade dos países do Norte, uma vez que a continuidade da dependência e marginalização destes é o que mantém o equilíbrio e poder do centro global. A periferia sofre não só com a pilhagem de recursos naturais e como espaço de exploração desenfreada - o extrativismo, a economia marrom como um todo, mineração -, como também serve de deposito de resíduos e sobras produzidos pelos padrões de consumo irreais e desbalanceados do sistema capitalista.

O relatório da Organização das Nações Unidas para Alimentação e Agricultura (FAO) de 2020 apontou que entre o período de 1979 e 2019, houveram mais de 2300 desastres ambientais na região da América Latina e Caribe, gerando aproximadamente 500 mil mortes e forçando uma situação de vulnerabilidade em 297 milhões de latino-americanos e caribenhos (FAO, 2020). Também, em 2020, o Escritório das Nações Unidas para a Coordenação de Assuntos Humanitários (OCHA), em parceria com a Comissão Econômica da América Latina (CEPAL), emitiram um relatório afirmando que entre o período de 2000 e 2019, o continente sofreu um prejuízo de 1 bilhão de dólares com os impactos de 12 grandes enchentes que afetaram não só as estruturas de produção e plantio, como também as áreas urbanas e industriais. A América Latina e o Caribe são, hoje, a região mais vulnerável aos efeitos das mudanças climáticas e aos desastres naturais devido à grande dependência às práticas que tem grande impacto negativo na natureza e à grande instabilidade e vulnerabilidade social no continente.

Os "crimes a céu aberto", como são caracterizados crimes ambientais, são frequentes em territórios vulneráveis, como a América Latina. A extrema dependência de regiões a práticas extrativistas, mineradoras e demais atividades poluentes e agressivas ao ecossistema resultam em áreas mais afetadas por desastres naturais, como o desastre da barragem de Mariana (Minas Gerais, Brasil) e a mina de Buenavista do Cobre (Sonora, México). Em ambos os casos, as práticas de exploração da região e a 
dependência direta de cidades menores expostas à instabilidade da estrutura local eram financiadas e operadas em parceria do capital nacional e estrangeiro; a Empresa Samarco filial da Vale em parceria com a empresa britânica-australiana Bhp Billiton e o Grupo México operado pela filial estadunidense Southern Cooper Corporation, respectivamente 4

É em decorrência desta contribuição para o sistema capitalista contemporâneo e a relação da exploração agressiva dos recursos naturais e suas consequências contemporâneas que é possível analisar com um olhar crítico as razões das investidas agressivas e aceleradas do capital sobre a natureza e o porquê da mercantilização e da financeirização tornarem-se práticas de acumulação permeáveis e figurativamente menos violentas, mas não menos desiguais e abusivas. A visão de David Harvey (2006, apud MISOCZKY E BÖHM, 2012, p. 553) aproximam-se da necessidade de superação das crises de superacumulação e dos curtos intervalos entre as crises de instabilidade dos impérios capitalistas através dos mecanismos neoliberais para a redistribuição da riqueza e da renda tanto das massas da população para a burguesia quanto dos Estados periféricos para os Estados centrais.

\section{Conceitos relacionados a trocas ecológicas desiguais e custos ambientais}

Sobre a percepção materialista e como esta impacta a análise socioambiental, Moore (ibidem, p. 448-450) contrasta a visão de Braudel (1977, p. 47 apud MOORE, 2003, p. 448) de capital como um recurso, como algo "tangível" porém "em constante trabalho", com a visão de Marx do capital como "uma relação de produção social definida, pertencente a uma formação histórica de sociedade definida" (MARX, 1967 apud MOORE, 2003, p. 450, tradução nossa). A chave está na diferença de capital como recurso e capital como relação, com a primeira opção relegando o processo de acumulação à administração de recursos e a segunda abrindo a possibilidade da acumulação como um processo que exige contato recíproco entre duas partes. Essa relação recíproca permite uma interpretação histórica na qual há uma evolução mútua entre sociedade e ambiente a partir do materialismo histórico-geográfico de Marx e Engels. Isso é evidente através da análise de Marx (1976, p. 283 e 290 apud FOSTER, 1999, p. 380) da relação humano-ambiente na qual o indivíduo controla sua relação metabólica com a natureza através do trabalho, que mobiliza os fluxos materiais entre os dois (MARTÍNEZ-ALIER in HORNBORG et al, 2007, p. 223). Neste mesmo trecho, Marx (apud FOSTER, 1999, p. 380) descreve o ser humano como um ser natural utilizando sua própria força, proveniente da natureza, para lidar com a matéria natural presente no solo, deixando clara uma visão divergente do maniqueísmo excludente do humano. Nesta visão de Marx, o ser humano é parte do mesmo meio, ele e o ambiente são considerados membros do mesmo "mundo" natural. Ambiente e humanidade moldam-se mutuamente pois, uma vez que o meio dá uma configuração dada e limitante com a qual o indivíduo deve trabalhar, as alterações do indivíduo sobre o ambiente resultam numa configuração diferente que será herdada pelos atores futuros, humanos ou não, gerando um ciclo transformativo (MOORE, 2003, p. 449 e 450). 
Dessa percepção da relação simbiótica e recíproca entre humanidade e ambiente surge outro conceito, apresentado por Foster (1999, p. 371-383), útil para a análise ambiental sob o capitalismo, incluindo as relações díspares entre centro e periferia. Tal conceito é a ruptura metabólica entre campo e cidade, mencionada tanto por Moore (ibidem) quanto por Wallerstein (in HORNBORG et al, 2007, p. 381) e Martínez-Alier (ibidem, p. 222), que é compreendida como um desequilíbrio na relação entre humano e solo (ou ambiente, numa compreensão ampliada) na qual há uma retirada constante dos nutrientes do solo através de exploração intensiva e seu transporte para longe através do comércio de longa distância, resultando num empobrecimento crescente e numa necessidade constante de restauração do solo (FOSTER, 1999, p. 379 e 380). Presente nas críticas de Marx sobre a agricultura de grande-escala, este conceito foi desenvolvido de acordo com pesquisas sobre exaustão do solo realizadas por químicos e agrônomos, como Justus von Liebig, demonstrando uma utilização direta de trabalhos das ciências naturais (FOSTER, 1999, p. 378; MARTÍNEZ-ALIER, J., 2007, p. 222) que enriqueceram sua análise sociológica e político-econômica. A ruptura metabólica consiste da transferência de nutrientes e riqueza do solo para longe das áreas produtivas através de uma lógica comercial de longas distâncias e de concentração populacional urbana, empobrecendo o ambiente e tornando-o menos produtivo.

Martínez-Alier (ibidem, p. 231) cita a tabela de 1885 feita por Patrick Geddes, inspirada pela Tableau Economique de Quesnay, como relevante para o desenvolvimento de uma teoria de trocas ecológicas desiguais na atualidade. A tabela de Geddes trata da transformação de energia e materiais em produtos através de extração, manufatura, transporte e troca, com estimativas sobre as perdas de energia e matéria através de dissipação e desintegração em cada estágio. De acordo com a lógica de Geddes, o que produto líquido não é baseado no valor adicionado, e sim no que resta, medido em energia e materiais ainda disponíveis. Quanto maior a dissipação de energia em um produto, maior seu preço.

Desta lógica, somada à ruptura metabólica de Marx, desenvolve-se o conceito das trocas ecológicas desiguais através dos diferentes efeitos sobre as ecologias locais. Martínez-Alier (ibidem, p. 231-234) utiliza o exemplo dos impactos das trocas de marfim e ouro, bens de luxo e, portanto, alheios à barreira analítica do sistema-mundo de Wallerstein (GOLDFRANK, 2000, p. 166), porém com diferenças significativas sobre as ecologias das regiões extratoras (desequilíbrio populacional de certas espécies ou extinção, poluição de água e solo para a mineração de ouro) e das regiões importadoras, que praticamente não recebem impacto em seus ambientes naturais com a recepção de produtos finalizados. Hornborg (1998) apresenta as perspectivas de alguns autores sobre a relação entre gastos de energia e trocas desiguais, argumentando sobre centros urbanos desenvolvidos como importadores de matéria e de energia que reexportam os bens produzidos gastando matéria e energia retirada, a preços inferiores, de outras regiões. Mais significativa que a questão da energia, pelo menos para este artigo, é a lógica derivada das observações de Hornborg (2009), que traça argumentos sobre questões distributivas de problemas ambientais, tratando-os com uma lógica de jogo de soma zero. 
A lógica apresentada é de que o valor atribuído é relativo à dissipação de energia e matéria para produzir os itens. Há bens que causam impactos sociometabólicos nos países receptores, como fontes de energia, mas que mantêm boa parte de seus aspectos poluidores nos ambientes de extração. Além das diferenças calculadas em massa ou energia, há a poluição através da extração, manufatura e transporte, com o exemplo das taxas de CO2 por dólar exportado, além de desastres ambientais, perda de nutrientes do solo, desequilíbrios populacionais. O ponto central das trocas ecológicas desiguais para o qual desejamos trazer atenção através deste trabalho é a diferença de fluxos líquidos de matéria e energia e, principalmente, de impactos ambientais entre os países periféricos e centrais.

Também é interessante citar a teoria da deterioração dos termos de troca desenvolvida por Prebisch (1949, apud MARTÍNEZ-ALIER in HORNBORG et al, 2007, p. 233), que, juntamente com o poder militar, funciona como um pilar de manutenção das trocas ecológicas desiguais através da necessidade de uma crescente quantidade de exportações para obter uma decrescente quantidade de importações, medidas em matéria e energia. Essa teoria enriquece esta perspectiva analítica por deixar clara a ideia de que os países periféricos no sistema-mundo cumprem um papel especializado nas extrações primárias para garantir a manutenção do sócio-metabolismo do centro do sistema, apesar desses aspectos metabólicos não terem sido propostos por Prebisch à época.

Além disso, Prebisch (1949, p. 71-80) destacava o modelo de oferta-demanda dupla que os países periféricos eram forçados a exercer para sobreviver dentro do sistema. Além da dinâmica natural da economia interna, essas economias participavam de uma mecânica agressiva e desigual de demanda altíssima com pouquíssima oferta e, muito menos, valorização das exportações agrícolas e matérias primas.

Como apresentado por Medeiros e Serrano, além de poderio bélico, produtividade econômica e influência monetária, o desenvolvimento tecnológico também é uma assimetria responsável por desenvolvimentos desiguais num contexto de capitalismo desregulado (MEDEIROS e SERRANO in FIORI, 2012, p. 119-122). Considerando que a tecnologia constitui mecanismos pelos quais o ser humano transforma o ambiente em que vive, é válido associá-la diretamente ao nível de desenvolvimento, considerando que a relação entre sociedade e ambiente é moldada com base nas características ecológicas da região. Tais características, por sua vez, são alteradas por processos de extração, transformação ou distribuição de recursos materiais ou energéticos por meio da tecnologia e da organização humana. A atenção a essa relação cíclica de transformação, que estabelece as bases para potencial exploração econômica e, consequentemente, desenvolvimento, deve ser considerada, como afirma Bunker (in FREY et al, 2019, p. 13-15). Considerando a importância da relação de transformação mútua entre economia e ambiente por meio da tecnologia, é válido compreender que o nível técnico afeta essa relação.

Assim, é possível retornar à crítica de Hestermeyer sobre a impossibilidade de países subdesenvolvidos operarem no sistema formal de obrigações da mesma forma que os desenvolvidos, principalmente no que tange à questão ecológica. Além de ser fruto da disparidade de níveis de 
desenvolvimento, essa impossibilidade também aprofunda a própria disparidade, de acordo com a lógica apresentada pelos autores citados anteriormente, como Bunker, Prebisch, Martínez-Alier e Marx.

\section{As consequências do imperialismo degradativo expostas na pandemia global}

A situação de calamidade que o mundo enfrenta atualmente, infelizmente, atinge setores além da saúde pública. Os impactos da COVID-19, somado a crise financeira gerada pela crise de combustíveis fósseis e investimento das produções em massa resultará em uma onda de impacto bastante avassaladora para a periferia mundial. Além disso, essas economias enfrentam uma assolação em sua estrutura social com índices altíssimos de desemprego, taxas de mortalidade em ascensão devido ao descontrole sanitário e dos setores de saúde referente à contenção da pandemia e, não menos importante, os avanços dos impactos climáticos e ambientais nas regiões marginalizadas.

Como exposto nas seções anteriores deste artigo, o padrão de solidificação do poder imperialista se dá através de ciclos de expansão e acumulação por espoliação, transferindo-se para além do capital financeiro, como também para o capital material e natural, resultando na pilhagem do meio ambiente nas regiões mais afastadas dos blocos de poder hegemônicos. Contudo, um estudo desenvolvido pela London School of Economics (LSE) apresenta indicativos de que a resposta para a superação da crise eminente que se aproxima do sistema internacional - e muito mais rapidamente e violentamente da periferia - pode e deve se apresentar através de uma resposta verde.

É de fácil entendimento a preocupação dos Estados em desenvolvimento com a crise de petróleo e combustíveis fósseis que se desdobra diante do cenário internacional, uma vez que seu processo de industrialização e produção para exportação é sustentado, em sua grande maioria, pela dependência da queima de combustíveis fósseis para energia e produção primária. Essa dependência e posicionamento dos países em estado de desenvolvimento são, consequentemente, produto da consolidação imperialista e os resultados da globalização financeira no mercado internacional.

Segundo Amir Lebdiou (2020, n.p.), do Centro de Estudos Latinoamericanos e do Caribe da LSE, 54\% dos países soberanos são dependentes da exportação de commodities e, consequentemente, são os países mais afetados pela crise da pandemia COVID-19. Ásia, África e América Latina e Caribe apresentam predominância da necessidade e dependência dos commodities minerais, agrícolas e energéticos para sua estrutura e produção, resultando diretamente na vulnerabilidade climática, sustentável e sanitária das regiões.

\section{Conclusão}

Com o objetivo de demonstrar as relações entre teorias do imperialismo e críticas e conceitos modernos sobre as dinâmicas de dominação entre Estados, economias e meio-ambiente, podemos concluir com uma série de correlações sobre os objetos analisados. Utilizando as contribuições de Harvey 
(2006; 2005), é possível observar a área ecológica como uma das esferas estruturais dominadas por ações imperialistas partindo do Estado hegemônico ou dos países centrais, sendo um meio de controle sobre os periféricos. A dominação é exercida de modo a engessar a configuração do sistema internacional e, também, a aprofundar suas disparidades.

Assim, criam-se dinâmicas de curto, médio e longo prazo. Os ciclos hegemônicos de Arrighi (1994), sendo geridos pela intensidade de acumulação, claramente são afetados pelos processos de médio e curto prazo que permitem a monopolização do capital e afetam as disparidades entre economias nacionais e que fortalecem os setores centrais do sistema interestatal capitalista. Essa monopolização do capital não se dá apenas no sentido financeiro, mas também no tecnológico que muito impacta nos outros setores. Além da financeirização de questões ambientais, o estabelecimento de regras a nível sistêmico que são pressionadas contra países subdesenvolvidos torna quase obrigatório o desenvolvimento ou a importação de tecnologias que estão disponíveis somente nos centros do sistema. Ou seja, além das vantagens de acumulação típicas da disparidade tecnológica e intensificadas pelas divergências legislativas ambientais, que permitem extração mais lucrativa a empresas competitivas vindas de ambientes ricos em capital financeiro e tecnológico, também há uma imposição de acumulação por exportação científica. Países subdesenvolvidos, nesse contexto, têm duas opções. Em primeiro lugar, podem contar com a exploração ambientalmente destrutiva provocada por uma confluência de fatores que incluem fracas legislações ambientais e falta de pressão política sobre indústrias extrativistas ou produtivas, sejam nacionais ou estrangeiras, correndo o risco de terem suas exportações estranguladas por normas vindas do centro do sistema através de imposições de barreiras comerciais com justificativas ecológicas. Em segundo lugar, podem optar por desenvolver suas próprias tecnologias verdes de modo a não só reduzir o impacto ambiental como também a atender as demandas dos centros do sistema ou, no caso mais comum devido ao atraso técnico e à falta de capital, simplesmente importar tais tecnologias e técnicas do centro, contribuindo para a disparidade de acumulação. Destas duas formas, a questão ambiental é utilizada como mecanismo estrutural de dominação e de monopolização ou controle do capital. Enquanto fatores de curto prazo podem ser citados como a questão de importação tecnológica ou de estrangulamento comercial, que também forçam a disparidade sistêmica, a relação simbiótica e de constante transformação mútua entre sociedade e natureza pode ser vista como um fator de médio prazo que também é um pilar sustentador do imperialismo.

Quanto às teorias clássicas do imperialismo, há correlações a serem estabelecidas com ambas. A matriz "civilizatória", típica do discurso reformista, é presente na relação de "levar tecnologia e um mundo melhor e mais saudável" aos subdesenvolvidos. Ou seja, há um claro discurso de "oferta de um mundo melhor" que impõe obrigações vindas dos centros do sistema que, boa parte das vezes, são dificilmente adotadas de forma fácil pelos subdesenvolvidos, que não têm capacidade financeira para arcar com estas imposições, como afirma Hestermeyer. Da visão revolucionária, é razoável argumentar sobre a 
questão ecológica como um mecanismo de dominação que é mais um meio pelo qual o imperialismo, como fase natural do capitalismo, se mantém e garante o acúmulo concentrado de capital.

Diante do apresentado, torna-se possível a identificação do investimento avançado e agressivo do capital à natureza como uma das etapas de um novo ciclo de acumulação, caracterizado por Harvey como "acumulação primitiva". A forma orgânica do capital se caracteriza pela necessidade de difusão de suas raízes de poder e, continuamente, a busca por esferas que possuem potencial para a exploração. Essa característica primitiva do capital de incentivo à competitividade, acumulação ilimitada para um crescimento ilimitado e a maximização de lucros no menor espaço de tempo possível não são compatíveis ao recurso natural e a matéria prima necessária para acompanhar esse processo de crescimento. $\mathrm{O}$ ideal do capitalismo liberal de crescimento ilimitado não é compatível com o mundo limitado e a necessidade de distribuição equiparada para o desenvolvimento daqueles Estados que se encontram marginalizados pelo processo de expansão imperialista.

Como citado anteriormente, a financeirização faz parte desta dominação e controle ao domínio pouco ou mal explorado, encontrando uma possibilidade de reafirmação do poder e controle do acesso de recursos aos demais componentes do sistema internacional que dependem do direcionamento do Estado dominador. Ao ser utilizada como mecanismo de dominação, a questão ecológica ou ambiental torna-se, assim, uma espécie de imperialismo verde.

\section{Referências:}

ALMEIDA FILHO, Niemeyer; PAULANI, Leda Maria. Regulação Social e Acumulação por Espoliação. Economia e Sociedade, v. 20, n. 2, 2011. Disponível em: < https://doi.org/10.1590/S0104$06182011000200002>$.

ARRIGHI, G. The long twentieth century: money, power and the origins of our time. London: Verso, 1994.

BAMBIRRA, Vânia. O capitalismo dependente latino americano. Florianópolis. Insular, 2012.

BORÓN, Atilio. América Latina en la geopolítica del imperialismo. Ediciones Luxemburg. Buenos Aires, Argentina. 2012.

BRAUDEL, Fernand. Escritos Sobre a História. São Paulo: Editora Perspectiva, 1978.

BUNKER, Stephen G. Toward a theory of ecologically unequal exchange. In: FREY, R. S.; GELLERT, P. K.; DAHMS, H. F. Ecologically Unequal Exchange: environmental injustice in comparative and historical perspective. London: Palgrave Macmillan, 2019. p. 13-48.

DEL ROIO, Marcos. Breve nota sobre a teoria do imperialismo. São Paulo: Novos Rumos/UNESP. v. 22, n. 47, p. 33-39, 2007.

DOS SANTOS, Theotonio. Esquema de Investigacíon sobre Relaciones de Dependencia en America Latina (Bosquejo Informativo). In: RIVERA, M. del Carmen del Valle; VILLAZUL, S. J. Jasso (eds.). Obras Reunidas de Theotonio dos Santos, 'Documento Fundacional'. México, D.F.: Instituto de Investigaciones Económicas, Universidad Nacional Autónoma de México (UNAM), 2015. 
DOS SANTOS, T. Latin American Underdevelopment: Past, Present and Future. A Homage to André Gunder Frank. In: CHEW, Sing C.; DENEMARK, Robert A. (eds.). The Underdevelopment of Development: Essays in Honour of Andre Gunder Frank. Thousand Oaks: Sage Publications, 1996.

DOS SANTOS, Theotonio. La teoría de la dependencia: balances y perspectivas. Madrid: Plaza Janés, 2002.

FOSTER, J. B. Marx's Theory of Metabolic Rift: Classical Foundations for Environmental Sociology. Chicago: American Journal of Sociology, v. 105, n. 2, 1999, p. 366-405.

GOLDFRANK, Walter L. Paradigm Regained? The Rules of Wallerstein's World-System Method. Pittsburgh: Journal of World-Systems Research, v. 6, n. 2, p. 150-195, 2000.

HARVEY, David. Spaces of global capitalism: towards a theory of uneven development. London: Verso, 2006.

HESTERMEYER, Holger P. Reality or Aspiration? Solidarity in Environmental and World Trade Law. In: HESTERMEYER, Holger; WOLFRUM, Rüdiger. Coexistence, Cooperation and Solidarity. Leiden: Martinus Nijhoff Publishers, 2012.

HORNBORG, Alf. Towards an ecological theory of unequal exchange: articulating world system theory and ecological economics. Cambridge: Ecological Economics, v. 25, p. 127-136, 1998.

HORNBORG, Alf.. Zero-Sum World: challenges in conceptualizing environmental load displacement and ecologically unequal exchange in the world-system. Thousand Oaks: International Journal of Comparative Sociology, v. 25, p. 237-262, 2009.

MARTÍNEZ-ALIER, Joan. Marxism, Social Metabolism, and International Trade. In: HORNBORG, Alf; MARTÍNEZ-ALIER, Joan; WALLERSTEIN, Immanuel M. Rethinking Environmental History: World-System History and Global Environmental Change. Lanham: Altamira Press, 2007.

MEDEIROS, Carlos A. e SERRANO, Franklin. Padrões monetários internacionais e crescimento. In: FIORI, José Luís (org.). Estados e moedas no desenvolvimento das nações. Petrópolis: Vozes, 2012.

MISOCZKY, Maria Ceci; BÖHM, Steffen. Do desenvolvimento sustentável à economia verde, a constante e acelerada investida do capital sobre a natureza. Rio de Janeiro: Cad. EBAPE.BR, v. 10, n. 3, p. 546-568, 2012.

MOORE, Jason W. Capitalism as World-Ecology: Braudel and Marx on Environmental History. London: Organization Environment, v. 16, n. 514, p. 431-458, 2003.

SMITH, Neil. Uneven development: Nature, capital, and the production of space. Athens: University of Georgia Press, 1984.

SOMMER, Jamie M.; SHANDRA, John M.; COBURN, Carolyn. Mining Exports Flows, Repression, and Forest Loss: A Cross-National Test of Ecologically Unequal Exchange. In: FREY, R. S.; GELLERT, P. K.; DAHMS, H. F. Ecologically Unequal Exchange: environmental injustice in comparative and historical perspective. London: Palgrave Macmillan, 2019.

WALLERSTEIN, Immanuel. Braudel and Interscience: a preacher to empty pews? Albany: Review (Fernand Braudel Center), v. 24, n. 1, p. 3-12, 2001.

\footnotetext{
Notas

${ }^{1}$ Mestranda em Economia Política Internacional no Programa de Pós-Graduação em Economia Política Internacional, Instituto de Economia, Centro de Ciências Jurídicas e Econômicas, Universidade Federal do Rio de Janeiro. Currículo Lattes: http://lattes.cnpq.br/7184582478006185. Orcid: https://orcid.org/0000-0003-0370-2713. E-mail: stelitanoamanda@gmail.com.

2 Mestrando em Economia Política Internacional do Programa de Pós-Graduação em Economia Política Internacional, Instituto de Economia, Centro de Ciências Jurídicas e Econômicas, Universidade Federal do Rio de Janeiro. Pesquisador do grupo de
} 
Pesquisa em Grande História (Big History) - http://dgp.cnpq.br/dgp/espelhogrupo/682413. Currículo Lattes: http://lattes.cnpq.br/7167073580143828. Orcid: https://orcid.org/0000-0002-0486-4266. E-mail: gabrielgr0191@gmail.com.

3 Ver The Closing Circle: Nature, Man and Technology. (COMMONER, Barry. 1971. New York).

4 Outros exemplos como a tragédia em San Juan, Argentina, com a poluição de resíduos de minério na nascente do degelo da Cordilheira dos Andes, contaminando diversos rios principais de fornecimento das cidades argentinas - a empresa responsável por esse crime ambiental, Barrick Gold, também é financiada pelo capital estrangeiro originado do Canadá.

Recebido em: 15 de junho de 2021 Aprovado em: 10 de setembro de 2021 